\title{
Analisis Kelayakan Usahatani Pembibitan Pala (Myristica Fragrans Houtt) Pola Sambung Pucuk Di Kabupaten Aceh Selatan
}

\author{
Muhammad Ismail1, Rachman Jaya 2, Basri A Bakar ${ }^{3}$, Asis ${ }^{4}$, Mehran 5, Abdul Azis ${ }^{6}$ \\ 1,2,3 Balai Pengkajian Teknologi Pertanian Aceh \\ email:muhammadismail@pertanian.go.id \\ Diterima: Juni 2021, Disetujui: Juni 2021, Diterbitkan: Juni 2021
}

\begin{abstract}
Abstrak
Penelitian ini dilaksanakan di provinsi Aceh dari bulan Oktober hingga Desember tahun 2018. Kabupaten Aceh Selatan dipilih sebagai lokasi penelitian karena merupakan salah satu sentra produksi pala selain Kabupaten Aceh Barat Daya. Tujuan penulisan untuk menganalisis kelayakan usahatani pembibitan pala pola sambung pucuk. Penelitian ini menggunakan metode survey terstruktur, observasi, dan wawancara langsung dengan responden menggunakan kuesioner. Data primer dikumpulkan dari enam orang penangkar, dan dua orang penentu kebijakan perkebunan di kabupaten Aceh Selatan. Sedangkan data sekunder dikumpulkan dari Badan Pusat Statistik (BPS), Dinas Pertanian Provinsi dan Kabupaten, dan Badan Penelitian dan Pengembangan Pertanian. Kelayakan usahatani pembibitan pala pola sambung pucuk dihitung melalui metode analisis input-output untuk mendapatkan nilai Beneficial Cost Ratio (B/C Ratio), dan Break Event Point (BEP). Secara ekonomis nilai B/C ratio sebesar 1,32 menunjukkan usahatani pembibitan pala pola sambung pucuk menguntungkan dan layak dikembangkan, dengan nilai Titik Impas Harga bibit sebesar Rp 15.113,75 per batang dan sebanyak 345,46 unit pada Titik Impas Produk yang diusahakan oleh para penangkar.
\end{abstract}

Kata Kunci:

pembibitan, pala, pucuk, kelayakan

\begin{abstract}
The feasibility Analysis of nutmeg nursery with bud grafting in Aceh Selatan District. This research was carried out in Aceh Province from October to December 2018. Aceh Selatan Distric was chosen as the research location because it was one of the nutmeg production centers besides the Aceh Barat Daya District. The purpose is to analize the feasibility of nutmeg nursery with bud grafting in Aceh Selatan District. This study used a structured survey method, observation, and interview using a questionnaire. Primary data was collected from six nurseries and two plantation policymakers in Aceh Selatan district. Secondary data were collected from the Central Statistics Agency (BPS), the Provincial and District Agricultural Service, and Indonesian Agency for Agricultural Research and Development. Feasibility of nutmeg nursery farming with bud grafting is calculated through the input-output analysis method to obtain the Beneficial Cost Ratio (B/C Ratio), and Break Event Point (BEP). Economically, the B/C ratio of 1.32 shows that nutmeg nursery, with the break-even price of IDR 15,113.75 and 345,46 units at the break-even point of the nursery products.
\end{abstract}

Keywords:

nursery, nutmeg, grafting

How to Cite: Muhammad Ismail, Rachman Jaya, Basri A Bakar, Asis, Mehran,Abdul Azis. (2021). Analisis Kelayakan Usahatani Pembibitan Pala (Myristica Fragrans Houtt) Pola Sambung Pucuk Di Kabupaten Aceh Selatan. Jurnal Penelitian Agrisamudra. 8(1):37-46

DOI: 10.33059/jpas.v8i1.3675 


\section{Pendahuluan}

Tanaman pala (Myristica fragrans Houtt) menjadi salah satu komoditas perkebunan ekspor utama dari Kabupaten Aceh Selatan. Biji dan kulitnya merupakan bahan baku olahan minyak atsiri dan bahan rempah-rempah, sedangkan daging buahnya dapat diolah menjadi berbagai macam produk seperti sirup pala dan manisan pala yang bernilai ekonomis cukup tinggi. Masyarakat Aceh Selatan sejak puluhan tahun lalu menjadikam tanaman ini sebagai penghasil utama bagi pendapatan keluarga.

Tahun 2017 tercatat luas penanaman pala kabupaten Aceh Selatan sebesar 16.289 ha dengan produksi mencapai 5.238 ton per tahun. Sentra produksi berada di Kecamatan Meukek, dan Tapaktuan masing-masing seluas 3.785 ha dan 2.177 ha (BPS, 2018). Namun sejak tahun 80-an tanaman ini terserang Hama Penggerek Batang (HPB) sekaligus penyakit Jamur Akar Putih (JAP) yang menurunkan populasi dan luas penanaman. Data BPS menunjukkan rata-rata luas penanaman baru pala di Provinsi Aceh sebesar 496,03 ha per tahun. Harni, et al. (2011) menyebutkan dari lima kecamatan di Aceh Selatan tingkat serangan JAP mencapai 100 persen, demikian pula yang terjadi di Provinsi Maluku (Kalay et al. 2015; Rehatta et al. 2016). Beberapa pelaku usaha seperti petani, pengusaha penyulingan, dan pengusaha produk olahan menyebutkan bahwa serangan JAP telah ada sejak awal tahun 1980 dan hingga saat ini belum dapat dikendalikan secara optimal.

Upaya pengendalian JAP secara biologis terus dilakukan pemerintah daerah, salah satunya melalui introduksi teknologi berbasis mikrorganisme yang menggunakan (Trichoderma strain lokal) dengan penambahan beberapa sumber karbodihrat sebagai prebiotik (Harni, 2011). Adapun dari sisi teknis, pengendalian JAP dan HPB dilakukan melalui inovasi bibit teknik sambung pucuk yang dikenalkan secara meluas oleh Forum Pala Aceh Selatan. Intoduksi sistem sambung pucuk menggunakan batang bawah dari pala hutan pada pembibitan sedangkan batang atasnya digunakan pala lokal dengan kategori produksi tinggi (Ruhnayat dan Djauhari, 2013). Petani meyakini bahwa penggunaan batang bawah pala hutan pada bibit akan mengurangi kematian pohon saat dipindah tanam ke kebun. Keyakinan ini didasarkan pada pala hutan tidak terserang JAP.

Meskipun keyakinan dan harapan petani sangat tinggi terhadap bibit pala pola sambung pucuk, namun demikian belum ditemukan tanaman pala hasil sambung pucuk yang telah berproduksi dengan baik dan tahan terhadap serangan hama dan penyakit utama tersebut ditanam dalam skala luas. Belum meluasnya penggunaan bibit sambung pucuk digunakan petani diduga karena harganya yang dinilai petani cukup mahal. Oleh sebab itu menarik untuk mengetahui kelayakan usahatani pembibitan pala pola sambung pucuk, serta titik impas harga dan produknya. 


\section{METODE}

Penelitian ini dilaksanakan dari bulan Oktober hingga Desember tahun 2018. Kabupaten Aceh Selatan dipilih sebagai lokasi penelitian karena merupakan sentra produksi pala selain kabupaten Aceh Barat Daya.

Penelitian ini menggunakan metode survei terstruktur, observasi lapang, dan wawancara langsung dengan responden menggunakan kuesioner. Data primer dikumpulkan dari enam orang penangkar, dan dua penentu kebijakan perkebunan kabupaten Aceh Selatan yakni Dinas Perkebunan, dan BAPPEDA. Selain itu informasi juga dikumpulkan dari Forum Pala Aceh kabupaten Aceh Selatan dan Universitas Syiah Kuala yang telah fokus menangani permasalahan pala di Aceh Selatan. Sedangkan data sekunder dikumpulkan dari Badan Pusat Statistik (BPS), Badan Penelitian dan Pengembangan Pertanian Kementerian Pertanian, Dinas Perkebunan, Dinas Perindustrian dan Perdagangan lingkup kabupaten Aceh Selatan.

Kelayakan usahatani pembibitan pala pola sambung pucuk dihitung melalui metode analisis input-output untuk mendapatkan nilai Beneficial Cost Ratio (B/C Ratio), dan Break Event Point (BEP). Analisis Return Cost Ratio digunakan untuk menentukan kelayakan usahatani yang merupakan nisbah antara penerimaan dan biaya. Secara matematis dapat ditulis sebagai berikut:

$$
\mathrm{a}=\mathrm{R} / \mathrm{C}
$$

Dimana: $\mathrm{a}=$ perbandingan biaya dan pendapatan; $\mathrm{R}=$ total penerimaan usahatani yang dijual dalam bentuk bibit sambungan (Rp); dan $C=$ total biaya usahatani (Rp). Jika a $>1$ : menunjukkan bahwa usahatani menguntungkan (feasible), jika $a<1$ : menyatakan usahatani tidak menguntungkan (infeasible), dan jika a=1 menunjukkan bahwa usahatani berada pada titik impas (break even point). (Soekartawi, 1986).

Selain mengetahui tingkat keuntungan dan kelayakan secara ekonomi, perlu pula dilakukan analisis Break Event Point (titik impas). Nilai ini akan menjadi petunjuk bagi petani untuk mengetahui capaian posisi usahataninya atas jumlah produksi dan keuntungan yang harus dicapai.

BEP atau titik impas dikelompokkan dari dua sisi, yakni produksi dan harga. Titik Impas Produksi (TIP) menggambarkan batasan minimal produksi yang harus dicapai agar usahatani tidak mengalami rugi. Secara matematis dapat diformulasikan sebagai berikut: TIP $=\left(\sum X i P X i\right) / P q$. Nilai TIP dihitung dengan cara membagi total biaya dengan harga satuan produk. Harapannya produksi aktual usahatani lebih tinggi dari nilai TIP yang diperoleh, artinya terdapat selisih jumlah produk yang merupakan nilai tambah produk. Dengan demikian semakin tinggi selisih jumlah produk aktual dengan nilai TIP maka semakin tinggi pula nilai tambah produk yang diperoleh.

Nilai Titik Impas Harga (TIH) perlu diketahui oleh petani untuk menentukan batasan harga minimal sekaligus nilai tambah ekonomi yang ingin diperoleh. Formula matematisnya sebagai berikut: $\mathrm{TIH}=\left(\sum X i P X i\right) / Q$, atau secara empiris TIH merupakan pembagian total biaya usahatani dengan total produksi yang dihasilkan. Semakin rendah nilai TIH dari harga aktual produk maka semakin tinggi nilai tambah ekonomi 
yang diperoleh dari usahatani tersebut. Nilai TIH dihitung dengan cara membagi total biaya dengan jumlah produksi (Hendayana, 2016). Hasil analisis kelayakan usahatani pembibitan pala pola sambung pucuk, peluang dan tantangan pengembangannya disajikan secara deskriptif.

\section{Hasil Dan Pembahasan}

\section{Gambaran umum lokasi penelitian}

Kondisi topografi kabupaten Aceh Selatan sangat bervariasi, terdiri dari dataran rendah, bergelombang, berbukit hingga pegunungan. Kabupaten Aceh Selatan memiliki luas wilayah sebesar 4.173,82 km² yang membujur dari Utara hingga Selatan. Kecamatan Kluet Tengah merupakan kecamatan terluas sekitar $801,08 \mathrm{~km}^{2}$, sedangkan kecamatan Labuhanhaji merupakan kecamatan dengan luas terkecil hanya $54,83 \mathrm{~km}^{2}$.

Berdasarkan elevasi (ketinggian dari permukaan laut) yang diukur dari Kantor Camat tiap kecamatan, tinggi wilayah kabupaten Aceh Selatan di atas permukaan laut (dpl) berkisar antara 2-74 $\mathrm{m}$ dpl. Wilayah tertinggi adalah kecamatan Kluet Tengah dengan ketinggian $74 \mathrm{~m}$ dpl, lalu kecamatan Meukek dan Labuhanhaji Barat pada ketinggian 35 m dpl. Kabupaten Aceh Selatan memiliki rata-rata curah hujan bulanan sebesar 75,16 mm hingga 699,02 mm dengan jumlah hari hujan sebanyak 4,67 hingga 21,1 rata-rata hari hujan dalam tahun 2017 (BPS, 2018).

Perkebunan pala di kabupaten Aceh Selatan umumnya menggunakan sumber bibit dari pulau Banda Provinsi Maluku dengan pengembangan terluas di kecamatan Meukek, Tapaktuan dan Labuhanhaji (Tabel 1). Tanaman pala menjadi penting bagi perekonomian masyarakat di Aceh Selatan, karena sebagian besar penduduknya menjadikan komoditas ini sebagai sumber penghasilan keluarga. Produksi pala turut menggerakkan ekonomi masyarakat dan sekaligus menambah pendapatan asli daerah (PAD). Adapun produksi pala di Aceh Selatan menunjukkan trend meningkat pada periode tahun 2006 - 2016 sebesar 7,48 persen per tahun (Gambar 1).

Tabel 1. Luas areal, produksi, produktivitas, jumlah petani pala Aceh Selatan tahun 2017

\begin{tabular}{lcccr}
\hline \multicolumn{1}{c}{ Kecamatan } & $\begin{array}{c}\text { Luas } \\
\text { Areal (ha) }\end{array}$ & $\begin{array}{c}\text { Produksi } \\
\text { (ton) }\end{array}$ & $\begin{array}{c}\text { Produktivitas } \\
\text { (kg/ha) }\end{array}$ & $\begin{array}{c}\text { Petani } \\
\text { (KK) }\end{array}$ \\
\hline Trumon & 12 & 4 & 600 & 21 \\
Trumon Timur & 40 & 17 & 750 & 47 \\
Trumon Tengah & 99 & 30 & 750 & 177 \\
Bakongan & 9 & 2 & 600 & 29 \\
Bakongan Timur & 105 & 45 & 750 & 206 \\
Kota Bahagia & 43 & 17 & 750 & 42 \\
Kluet Selatan & 32 & 10 & 650 & 59 \\
Kluet Timur & 72 & 26 & 789 & 209 \\
Kluet Utara & 299 & 95 & 771 & 815 \\
Pasie Raja & 960 & 286 & 789 & 1.351 \\
Kluet Tengah & 151 & 30 & 700 & 260 \\
Tapaktuan & 2.167 & 871 & 810 & 1.952 \\
Samadua & 1.804 & 630 & 830 & 1.855 \\
Sawang & 1.670 & 659 & 836 & 1.872 \\
\end{tabular}




\begin{tabular}{lrrrr} 
Meukek & 3.695 & 1.844 & 860 & 3.846 \\
Labuhanhaji & 1.821 & 750 & 835 & 2.602 \\
Labuhanhaji Timur & 1.619 & 249 & 810 & 1.810 \\
Labuhanhaji Barat & 1.223 & 183 & 752 & 1.032 \\
\hline \multicolumn{1}{c}{ Jumlah } & 15.821 & 5.748 & 757.33 & 18.185 \\
\hline
\end{tabular}

Sumber: BPS kabupaten Aceh Selatan, 2018

Perkebunan pala di kabupaten Aceh Selatan umumnya menggunakan sumber bibit dari pulau Banda Provinsi Maluku dengan pengembangan terluas di kecamatan Meukek, Tapaktuan dan Labuhanhaji (Tabel 1). Tanaman pala menjadi penting bagi perekonomian masyarakat di Aceh Selatan, karena sebagian besar penduduknya menjadikan komoditas ini sebagai sumber penghasilan keluarga. Produksi pala turut menggerakkan ekonomi masyarakat dan sekaligus menambah pendapatan asli daerah (PAD). Adapun produksi pala di Aceh Selatan menunjukkan trend meningkat pada periode tahun 2006 - 2016 sebesar 7,48 persen per tahun (Gambar 1).

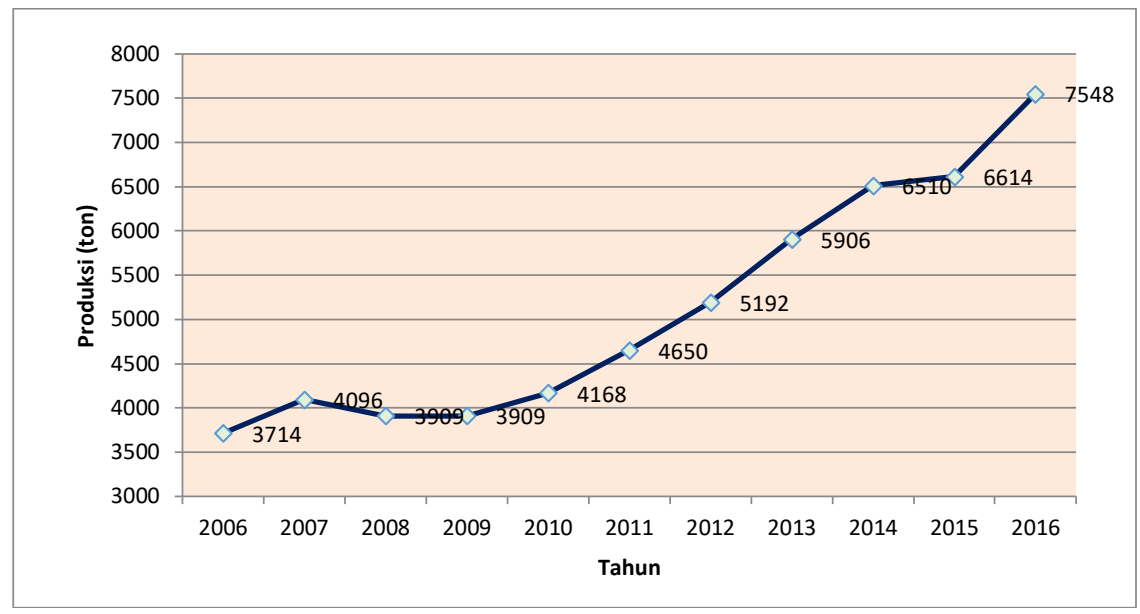

Sumber BPS Kabupaten Aceh Selatan, 2018

Gambar 1. Trend Produksi Pala di Kabupaten Aceh Selatan

\section{Karakteristik usahatani pembibitan pala pola sambung pucuk}

Bibit pala pola sambung pucuk diinisiasi oleh petani (Bapak Hamdani) dari desa Tapaktuan kecamatan Tapaktuan bersama Forum Pala Aceh Selatan. Berawal dari dugaan bila pala hutan yang tidak terserang JAP disambung dengan pala lokal yang berproduksi tinggi maka akan diperoleh individu baru yang ideal. Hal ini telah diungkapkan sebelumnya oleh Harni, et al (2011) dimana penggunaan pala hutan sebagai batang bawah didasarkan asumsi pala hutan memiliki kemampuan untuk bertahan terhadap serangan HPB dan JAP, yang banyak menjadi penyebab rusaknya pertanaman pala di kabupaten Aceh Selatan.

Inovasi teknologi ini kemudian berkembang pesat dan diterima oleh sebagian besar petani pala di Aceh Selatan. Dari hasil wawancara diperoleh informasi bahwa Forum Pala Aceh Selatan menyikapi perkembangan permintaan bibit pola sambung pucuk 
dengan mengedukasi petani agar mampu menghasilkan bibit secara mandiri, hingga meluaskan pemasarannya sampai ke luar Aceh. Disebutkan bahwa sebanyak 50.000 batang bibit pala sambung pucuk telah dikirim ke kabupaten Pagar Alam, Sumatera Selatan.

Pembibitan pala pola sambung pucuk yang dilakukan oleh petani penangkar dengan memanfaatkan benih pala hutan sebagai batang bawah dan pala unggul sebagai mata entresnya. Penyambungan pada bagian tunas embriotik bertujuan agar penyembuhan luka cepat terjadi dan kalus cepat terbentuk sehingga jaringan batang atas dan batang bawah cepat bersatu/bertaut. Teknik yang digunakan dalam sistem sambung pucuk komoditas pala secara epicotyl grafting dengan menggunakan batang bawah berumur 2030 hari merupakan cara terbaik dengan tingkat keberhasilan mencapai 80-90\%. Secara teknis epicotyl merupakan tunas embriotik di atas kotiledon tanaman pala.

\section{Penanaman bibit pala pola sambung pucuk di tingkat petani.}

Mahalnya harga bibit pala pola sambung pucuk yang ditawarkan oleh para penangkar membuat penanamannya belum meluas di tingkat petani, hanya digunakan sebagai pengganti tanaman yang mati. Harga yang ditawarkan oleh penangkar pada kisaran Rp 35.000-Rp 50.000 per batang. Selain harga bibit yang mahal, belum meluasnya penanaman pala pola sambung pucuk juga didasarkan atas penilaian petani terhadap kemampuan berproduksi serta daya tahannya terhadap HPB dan JAP yang belum teruji. Saat ini jumlah penangkar yang mampu menyediakan bibit pala pola sambung pucuk masih terbatas, di kecamatan Tapak Tuan hanya ditemukan 6 orang penangkar dengan kapasitas produksi sekitar 800-1.000 batang per tahun. Kondisi ini disebabkan tingkat keberhasilan penyambungan yang masih rendah ditambah terbatasnya sumber benih (pala hutan sebagai batang bawah), dan mata entres dari Kebun Bibit Induk (KBI). Kedua alasan ini turut menyebabkan belum meluasnya penanaman di lapangan. Pada saat yang sama petani belum mampu mengusahakan bibit pala pola sambung pucuk ini secara mandiri.

Adapun dari sisi penyediaan biji pala hutan sebagai batang bawah, petani membutuhkan waktu yang relatif lama untuk mengumpulkannya di samping risiko yang harus dihadapi. Disebutkan bahwa sebagian pala hutan tumbuh di tebing-tebing batu yang terjal sehingga menyulitkan untuk memperolehnya. Perlu dikaji penggunaan asuransi jiwa bagi petani pengumpul benih pala hutan tersebut.

\section{Kelayakan usahatani pembibitan pala pola sambung pucuk}

Menghitung kelayakan ekonomis suatu usahatani penting dilakukan oleh petani, namun hal ini sering tidak dilakukan. Tindakan mengumpulkan data dan input, serta mencatat pengeluaran dan perolehan hasil jarang sekali dilakukan petani, hanya mengandalkan ingatan saja.

Secara ekonomis usahatani pembibitan pala pola sambung pucuk cukup profitable bagi penangkar, terlihat dari besarnya nilai $\mathrm{R} / \mathrm{C}$ ratio yakni sebesar 2,32 yang lebih besar dari 1 (feasible). Nilai ini menunjukkan bahwa usahatani pembibitan pala pola sambung 
pucuk ini layak dan menguntungkan sehingga dapat diteruskan. Pernyataan ini didukung oleh nilai B/C ratio yang juga lebih besar dari 1, yakni sebesar 1,32.

Tabel 2 menunjukkan bahwa TIP sebesar 345,46 batang berada di bawah produksi aktual sebanyak 800 batang. Nilai ini menyatakan bahwa usahatani pembibitan pala pola sambung pucuk yang dilakukan petani memiliki nilai tambah sebesar 454,54 batang. Perolehan nilai tambah ini sekaligus menunjukkan nilai toleransi terhadap perubahan produksi yang tercapai.

Toleransi terhadap perubahan produksi pada usahatani pembibitan pala pola sambung pucuk tersebut mencapai angka 56,82\%. Angka ini diperoleh dengan cara membagi nilai tambah produksi (457,40 batang) dengan total produksi yakni sebesar 800 batang dikalikan 100. Semakin besar persentase toleransi maka semakin efisien usahatani yang dilakukan.

Tabel 2. Analisis input-output usahatani pembibitan pala pola sambung pucuk di Aceh Selatan

\begin{tabular}{|c|c|c|c|c|}
\hline Uraian & Volume & Satuan & Harga $(\mathbf{R p})^{*}$ & Jumlah (Rp) \\
\hline Biji pala hutan & 1.000 & butir & 2.000 & 2.000 .000 \\
\hline Polybag & 1.000 & lembar & 933 & 933.000 \\
\hline NPK & 3 & $\mathrm{~kg}$ & 6.000 & 18.000 \\
\hline Tanah humus & 3 & kubik & 200.000 & 600.000 \\
\hline Pupuk kandang & 1 & kubik & 100.000 & 100.000 \\
\hline Pengambilan biji & 2 & HOK & 100.000 & 200.000 \\
\hline Pembuatan naungan & 1 & unit & 3.000 .000 & 3.000 .000 \\
\hline Upah pengisian polybag & 3 & HOK & 100.000 & 300.000 \\
\hline Pindah dan susun polybag & 3 & HOK & 100.000 & 300.000 \\
\hline Penanaman & 3 & HOK & 100.000 & 300.000 \\
\hline Pemeliharaan (3 minggu) & 3 & HOK & 100.000 & 300.000 \\
\hline Pengambilan entres & 20 & HOK & 100.000 & 2.000 .000 \\
\hline Penyambungan & 4 & HOK & 100.000 & 400.000 \\
\hline Fungisida & 1 & bungkus & 40.000 & 40.000 \\
\hline Pemeliharaan (5-8 bulan) & 16 & HOK & 100.000 & 1.600 .000 \\
\hline Total biaya & & & & 12.091 .000 \\
\hline Harga jual & & & & 35.000 \\
\hline Penerimaan & 800 & batang & & 28.000 .000 \\
\hline Pendapatan & & & & 15.909 .000 \\
\hline $\mathrm{R} / \mathrm{C}$ ratio & & & & 2,32 \\
\hline $\mathrm{B} / \mathrm{C}$ ratio & & & & 1,32 \\
\hline TIP & & & & 345,46 \\
\hline TIH & & & & $15.113,75$ \\
\hline
\end{tabular}

Keterangan: * harga berlaku di Kabupaten Aceh Selatan

Nilai TIP menunjukkan jumlah penjualan minimal yang harus dijaga oleh petani agar tidak mengalami kerugian. Jumlah penjualan minimal ini sekaligus merupakan jumlah unit produksi yang harus dicapainya. Atau dengan lain perkataan bahwa nilai TIP menyatakan berapa jumlah produk yang harus terjual untuk memperoleh laba yang telah direncanakan. Pada kasus penelitian ini maka petani harus memproduksi sekaligus menjual sebanyak lebih dari 345,46 batang bibit atau digenapkan menjadi 346 
batang untuk memperoleh keuntungan dengan harga jual di atas Rp 15.113,75 per batang.

Bila dibagi dengan waktu yang dibutuhkan hingga bibit dapat dipasarkan yakni sekitar 8-10 bulan, maka penangkar memperoleh pendapatan sebesar Rp 1.590 .900 - Rp 1.988.625 per bulan. Nilai ini cukup memadai bila dibandingkan dengan upaya pemeliharaan khususnya penyiraman yang dilakukan sekali sehari (tergantung kondisi) bibit selama \pm 3 bulan. Nilai ini lebih besar bila dibandingkan dengan jumlah rata-rata pengeluaran sebulan di provinsi Aceh tahun 2018 yakni sebesar Rp 973.817 (BPS, 2019). Artinya usahatani pembibitan pala pola sambung pucuk yang diusahakan oleh petani di kabupaten Aceh Selatan layak untuk dikembangkan.

Sebagai pembanding, Widiatmaka, et al (2013) menguji secara spasial kesesuaian lahan untuk pengembangan komoditas kakao dan kelapa sawit di kabupaten Pidie Jaya. Mereka menyatakan TIH untuk kakao sebesar Rp 5.568 sedangkan kelapa sawit sebesar Rp 301, adapun TIP kedua komoditas tersebut masing-masing sebesar $505 \mathrm{~kg}$ dan 7.423 $\mathrm{kg}$. Demikian pula hasil penelitian Astanu et al., (2013) yang menyebutkan usahatani pala yang dilakukan secara intensif di kecamatan Gisting kabupaten Tanggamus menunjukkan nilai Net B/C Ratio 2,23, NPV sebesar Rp 123.574.036, payback period selama 10 tahun, dan Internal Rate Of Return (IRR) sebesar 20,98 persen sehingga secara finansial usahatani pala intensif layak diusahakan.

\section{Analisis Sensitivitas}

Analisis sensitivitas perlu dilalukan untuk memperkirakan kelayakan suatu usahatani pada masa depan akibat perubahan-perubahan yang mungkin terjadi. Kusuma dan Nur (2014) menyebutkan analisis sensitivitas dilakukan dengan cara mengubah variabel yang dapat mempengaruhi jalannya suatu usaha. Perubahan harga jual, harga input, tingkat suku bunga, biaya tenaga kerja, serta biaya transportasi adalah variabel umum yang mungkin terjadi akan mengubah perilaku pengelola usahatani maupun konsumen.

Tabel 3. Hasil analisis sensitivitas usahatani pembibitan pala pola sambung pucuk di kabupaten Aceh selatan

\begin{tabular}{ccccccccc}
\hline & \multicolumn{3}{c}{ Tingkat Perubahan } & \multicolumn{4}{c}{ Kriteria Kelayakan } \\
\cline { 2 - 8 } Kondisi & $\begin{array}{c}\text { Harga } \\
\text { Input }\end{array}$ & $\begin{array}{c}\text { Ongkos } \\
\text { Tenaga } \\
\text { Kerja }\end{array}$ & $\begin{array}{c}\text { Harga } \\
\text { Output }\end{array}$ & $\begin{array}{c}\text { R/C } \\
\text { ratio }\end{array}$ & B/C ratio & TIP & TIH \\
\hline 1 & $+40 \%$ & $+40 \%$ & Tetap & 1,65 & 0,65 & 483,64 & $21.159,25$ \\
2 & $+105 \%$ & $+105 \%$ & Tetap & 0,93 & $-0,07$ & 863,64 & $38.784,38$ \\
3 & $+40 \%$ & $+40 \%$ & $-40 \%$ & 0,99 & $-0,01$ & 806,07 & $21.159,25$ \\
\hline
\end{tabular}

Tabel 3 menunjukkan bahwa pada kondisi 1 usahatani pembibitan pala pola sambung pucuk masih menguntungkan walaupun seluruh input dan ongkos tenaga kerja naik hingga 40 persen dengan harga jual yang tetap (Rp 35.000/batang). Nilai TIH sekaligus merupakan batas harga yang akan dilepas oleh penangkar, kenyataan di lapangan bibit pala sambungan dilepas dengan harga yang jauh di atas $\mathrm{TIH}$. Beberapa petani 
menyebutkan harga yang dilepas pengangkar masih terlalu mahal sehingga sulit ditanam di kebunnya.

Sedangkan bila terjadi seperti pada kondisi 2 dan 3, petani akan merugi, hal ini disebabkan tidak tertutupinya biaya yang dikeluarkan dari penerimaan yang diperoleh. Meskipun demikian hasil analisis menunjukkan bahwa usahatani pembibitan pala sambung pucuk ini sangat elatis terhadap biaya usahatani mencapai 105 persen dengan harga jual yang tetap.

Bila dicermati lebih lanjut pada kondisi 1 penangkar akan memperoleh keuntungan sebesar selisih antara nilai TIH dengan harga bibit yang ditawarkan. Kondisi 1 ini merupakan kondisi yang paling relevan atau kemungkinan terjadi dibandingkan kondisi 2 dan 3. Kenaikan harga input, dan tenaga kerja, sekaligus penurunan harga jual yang tajam sangat jarang terjadi pada kondisi normal.

\section{Simpulan}

Usahatani pembibitan pala pola sambung pucuk memberikan keuntungan yang cukup besar karena harga jualnya yang tinggi. Nilai B/C ratio sebesar 1,32 menunjukkan usahatani pembibitan pala pola sambung pucuk ini layak dikembangkan. Usahatani ini tidak sensitif terhadap koreksi harga input maupun harga jualnya di Aceh Selatan. Selisih nilai antara TIH dengan harga yang ditawarkan penangkar sebesar Rp 19.886,25 merupakan laba yang diperoleh penangkar yang sesungguhnya masih dapat diturunkan demi tersebarnya bibit pala sambungan secara luas di tingkat petani. Tingginya harga bibit dan ketersediaannya di tingkat petani menyebabkan masih sedikit petani yang menanamnya pada lahan-lahan yang dimilikinya. Tulisan ini hanya terbatas pada usahatani pembibitan pala pola sambung pucuk, adapun daya tahan bibit terhadap penyakit JAP dan HPB masih perlu diuji lebih lanjut.

\section{Ucapan Terima Kasih}

Terima kasih penulis sampaikan Dinas Pertanian dan Perkebunan Provinsi Aceh yang telah menjalin kerjasama dan membiayai penelitian ini.

\section{Daftar Pustaka}

Astanu, D. A., Ismono, R. H., \& Rosanti, N. (2013). Analisis Kelayakan Finansial Budidaya Intensif Tanaman Pala Di Kecamatan Ginting Kabupaten Tanggamus. Jiia, 1(3), 218-225. http://jurnal.fp.unila.ac.id/index.php/JIA/article/view/576/538

Harni, R. (2011). Pengendalian Terpadu Hama dan Penyakit Utama Pala. Badan Litbang Pertanian, Agroinovasi, 3394, 13-16.

Balitbangtan, 2011. Pengendalian terpadu hama dan penyakit utama pala. Agroinovasi, Edisi 1 Maret 2011 No. 3394 Tahun XLI, Jakarta.

BPS, 2018. Kabupaten Aceh Selatan Dalam Angka. Geografi dan Iklim.

BPS, 2018. Kabupaten Aceh Selatan Dalam Angka. Luas Penanaman Komoditas Pinang, Kemiri, dan Pala.

BPS, 2019. Aceh Dalam Angka. Rata-rata Pengeleluaran Per Kapita Sebulan (Rupiah) Menurut Kelompok Barang, Maret 2015-2018. 
Harni R, Trisawa IM, dan Wahyudi A. 2011. Observasi dan identifikasi penyakit jamur akar pada tanaman pala di Kabupaten Aceh Selatan. Buletin RISTRI, 2 (3): 383-390.

Hendayana Rachmat, 2016. Analisis data pengkajian. [Buku] Jakarta IAARD Press, 2016.

Kalay AM, Lamerkabel JSA, Thenu FJL. 2015. Kerusakan tanaman pala akibat serangan penyakit busuk buah kering dan hama penggerek batang pala di Kecamatan Leihitu Kabupaten Maluku Tengah. Jur. Agroekotek 7 (2): 138- 146.

Kusuma, P.T.W.W, dan Nur, K.I.M. 2014. Analisa kelayakan finansial pengembangan usaha produksi komoditas lokal: mie berbasis jagung. AGRITECH, Vol. 34, No. 2, Mei 2014.

Rehatta H, Wattimena AY, Tupamahu F. 2016. Kajian produktivitas tanaman pala (Myristica Sp) di Kecamatan Kairatu Barat Kabupaten Seram Bagian Barat. J. Budidaya Pertanian, 12 (1):51-54:1858-4322.

Ruhnayat, A dan E. Djauharia. 2013. Teknik perbanyakan vegetatif tanaman pala dan cengkeh. Laporan Akhir Penelitian T.A. 2012. Balai Penelitian Tanaman Rempah dan Obat. 8 hal.

Soekartawi, S. 1986. Ilmu Usahatani dan Penelitian untuk Perkembangan Petani Kecil. Jakarta: UI Press.

Widiatmaka, Zulfikar, Syaiful Anwar, dan Wiwin Ambarwulan, 2013. Perencanaan spasial pemanfaatan lahan untuk komoditas perkebunan rakyat di Kabupaten Pidie Jaya, Provinsi Nanggroe Aceh Darussalam. Jurnal Ilmiah Geomatika Volume 19 No. 1 Agustus 2013: 40-48 